Research article

Open Access

\title{
A case-control study of rheumatoid arthritis identifies an associated single nucleotide polymorphism in the NCF4 gene, supporting a role for the NADPH-oxidase complex in autoimmunity
}

\author{
Lina M Olsson ${ }^{1}$, Anna-Karin Lindqvist ${ }^{1,2}$, Henrik Källberg ${ }^{3}$, Leonid Padyukov ${ }^{4}$, Harald Burkhardt ${ }^{5}$, \\ Lars Alfredsson ${ }^{3}$, Lars Klareskog ${ }^{4}$ and Rikard Holmdahl ${ }^{1}$
}

\author{
${ }^{1}$ Medical Inflammation Research, Lund University, BMC 111, 221 84, Lund, Sweden \\ ${ }^{2}$ Cartela AB, Box 709, SE-220 07 Lund Sweden \\ 3Institute for Environmental Medicine, Karolinska Institutet, Box 210, 171 77, Stockholm, Sweden \\ ${ }^{4}$ Rheumatology Unit, Department of Medicine, Karolinska Institutet, 171 76, Stockholm, Sweden \\ ${ }^{5}$ Division of rheumatology, Johann Wolfgang Goethe University, Theodor-Stern-Kai, 60596 Frankfurt am Main, Germany \\ Corresponding author: Lina M Olsson, lina.olsson@med.lu.se
}

Received: 22 Jul 2007 Revisions requested: 30 Aug 2007 Revisions received: 17 Sep 2007 Accepted: 26 Sep 2007 Published: 26 Sep 2007

Arthritis Research \& Therapy 2007, 9:R98 (doi:10.1186/ar2299)

This article is online at: http://arthritis-research.com/content/9/5/R98

(c) 2007 Olsson et al.; licensee BioMed Central Ltd.

This is an open access article distributed under the terms of the Creative Commons Attribution License (http://creativecommons.org/licenses/by/2.0), which permits unrestricted use, distribution, and reproduction in any medium, provided the original work is properly cited.

\begin{abstract}
Rheumatoid arthritis (RA) is a chronic inflammatory disease with a heritability of $60 \%$. Genetic contributions to RA are made by multiple genes, but only a few gene associations have yet been confirmed. By studying animal models, reduced capacity of the NADPH-oxidase (NOX) complex, caused by a single nucleotide polymorphism (SNP) in one of its components (the NCF1 gene), has been found to increase severity of arthritis. To our knowledge, however, no studies investigating the potential role played by reduced reactive oxygen species production in human RA have yet been reported. In order to examine the role played by the NOX complex in RA, we investigated the association of 51 SNPs in five genes of the NOX complex (CYBB, CYBA, NCF4, NCF2, and RAC2) in a Swedish case-control cohort consisting of 1,842 RA cases and 1,038 control individuals.
\end{abstract}

Several SNPs were found to be mildly associated in men in NCF4 (rs729749, $P=0.001), N C F 2$ (rs789181, $P=0.02)$ and RAC2 (rs1476002, $P=0.05$ ). No associations were detected in CYBA or CYBB. By stratifying for autoantibody status, we identified a strong association for rs729749 (in NCF4) in autoantibody negative disease, with the strongest association detected in rheumatoid factor negative men (CT genotype versus $\mathrm{CC}$ genotype: odds ratio $0.34,95 \%$ confidence interval 0.2 to $0.6 ; P=0.0001$ ). To our knowledge, this is the first genetic association identified between RA and the NOX complex, and it supports previous findings from animal models of the importance of reactive oxygen species production capacity to the development of arthritis.

\section{Introduction}

Rheumatoid arthritis (RA) is a chronic inflammatory disease that leads to erosion and deformation of the joints. The prevalence in the general population is $0.5 \%$ to $1 \%$, and women are at two to three times greater risk for developing the disease. Twin studies show a concordance rate of $12 \%$ to $15 \%$ in monozygotic twins and $4 \%$ in dizygotic twins, and the genetic heritability is estimated at $60 \%$ [1]. Despite much effort to identify arthritis causing genes, only few genetic loci have been confirmed to be associated with RA, among which are the human leucocyte antigen ( $H L A)$ locus and the protein tyrosine phosphatase non-receptor 22 gene (PTPN22) [2-4].

RA is a heterogeneous disease with symptoms and disease progression that vary between patients. Classification of typical RA requires fulfilment of four out of seven criteria established by the American College of Rheumatology [5]. The heterogeneity of the symptoms in RA probably mirrors the

$\overline{\mathrm{CCP}}=$ cyclic citrullinated peptide; $\mathrm{CEPH}=$ Centre d'Etude du Polymorphisme Humain; $\mathrm{Cl}=$ confidence interval; EIRA = Epidemiological Investigation of Rheumatoid Arthritis; HWE = Hardy-Weinberg equilibrium; NOX = NADPH oxidase; OR = odds ratio; RA = rheumatoid arthritis; RF = rheumatoid factor; ROS = reactive oxygen species; $\mathrm{SE}=$ shared epitope; SNP = single nucleotide polymorphism. 
underlying genetic contribution; hence, the various combinations of symptoms observed in patients are probably caused by different combinations of risk alleles.

In the search for markers that can predict development of the disease before its onset, several autoantibodies, including rheumatoid factors (RFs) and antibodies against cyclic citrullinated peptides (anti-CCP antibodies), have been detected [68]. RFs, autoantibodies that recognize the Fc part of immunoglobulins [9], are present in $60 \%$ to $70 \%$ of RA patients and have been found to be associated with more severe clinical manifestations [10,11]. Anti-CCP antibodies are present in $50 \%$ to $60 \%$ of RA patients and have also been shown to predict more severe disease [10,12-14]. Interestingly, recent data suggest that the HLA-DRB1 locus, which has been shown to be associated with RA, is only associated with the presence of anti-CCP antibodies, and this association is independent of both RA development and the presence of RFs [15]. Together with recent data describing the interaction between environmental factors and genetic predisposition [16,17], these findings support the hypothesis that several independent disease mechanisms may lead to development of RA. They also emphasize the need to use relevant subgroups of RA patients in genetic association studies.

Various approaches have been used to identify genes that contribute to common diseases such as RA [18,19]. Because of increasing knowledge of gene functions and immunological pathways, a candidate gene approach can be more efficient in terms of both cost and time than traditional linkage analysis or genome-wide approaches. The selection of genes in a candidate gene study can be based on previous knowledge of gene functions as well as on disease or immunological mechanisms. It can also be based on findings in animal models.

The Pia4 locus in rats has been shown to reduce the severity of pristane-induced arthritis (an arthritis model) [20]. A single nucleotide polymorphism (SNP) in the Ncf1 gene was found to be responsible for the protective effect [21]. Ncf1 encodes the protein p47phox, which is part of the NADPH-oxidase (NOX) complex that produces reactive oxygen species (ROS) in response to infectious stimuli. Rats carrying the risk allele have reduced capacity to produce ROS, which is linked to increased risk for development of arthritis [21,22]. Apart from NCF1, the NOX complex is composed of five other proteins encoded by the genes NCF2, NCF4, CYBB, CYBA and RAC2 [23,24]. In phagocytes massive ROS production, called the oxidative burst, takes place in the phagosome or endosome (intracellular) or in the plasma membrane (extracellular) after ingestion of invading pathogens or after stimulation of innate immune receptors [25-27]. However, the ability to generate ROS extends to cells other than classical phagocytes, such as dendritic cells, suggesting that the NOX complex has additional functions in the immune system [28]. Interestingly, recent findings from our group show that the redox balance of T-cell membranes has an important effect on the activation and proliferation of T cells [29].

Results obtain in animal models make NCF1 and the other genes of the NOX complex candidate genes for human RA. However, transferring animal data to the human setting is not straightforward in this case. In contrast to rats, the genomic organization of NCF1 in humans is very complex, which makes SNP-based association analysis difficult [30,31]. However, because of the complex interplay between the proteins of the NOX complex, it is likely that genetic changes in any of the genes could have the same effect on ROS production, as is seen for $\mathrm{Ncfl}_{1}$ in rats.

We used a candidate gene approach to study the association with RA of 51 SNPs in five genes included in the NOX complex. We found a SNP, located in intron 4 in NCF4, to be associated with RA in a Swedish case-control cohort. This supports the hypotheses that the NOX complex is involved in the development of RA and that ROS could be an important regulator of the immune system.

\section{Materials and methods Selection of single nucleotide polymorphism}

The HapMap genome browser [32] was used as the primary source for selection of SNPs. Primarily, HapMap-validated SNPs were selected. However, in order to obtain evenly dispersed SNPs across the genes, SNPs were also selected from dbSNP [33]. The selection was based on several criteria; the minor allele frequency should be more than $5 \%$ in the Centre d'Etude du Polymorphisme Humain (CEPH) or other European cohort, the SNP should be located in a nonrepetitive sequence, and the validation status at dbSNP should be at least two-hit. We also consulted the Linkage disequilibrium (LD) maps of the HapMap CEPH samples in order to disperse evenly the SNPs with respect to the LD structure. Sixty-seven SNPs were selected (see Additional file 1): six in CYBB, eight in CYBA, 22 in NCF2, 21 in NCF4 and 10 in RAC2. The number of SNPs selected in each gene reflects both the size of the gene and the availability of validated SNPs.

\section{Samples}

Samples from the Epidemiological Investigation of Rheumatoid Arthritis (EIRA), a population based case-control study, were analyzed. The study base comprised the population, aged 18 to 70 years, in a geographically defined area in the middle and southern parts of Sweden during the period from May 1996 to 2005. A case was defined as a person in the study base who, during the study period and for the first time, received a diagnosis of RA based on the American College of Rheumatology criteria of 1987 [5]. All cases were examined and diagnosed by a rheumatologist at a participating centre. All public rheumatology units in the study area and almost all of the (very few) private units participated in the study. The present study includes data from 1,842 RA patients and 
1,038 controls, randomly selected from the study base and matched on age, sex and residential area. Of the cases and controls, $71 \%$ and $72 \%$, respectively, are female; the mean age was $51 \pm 13$ years in cases and $54 \pm 12$ in controls. Information about RF and anti-CCP antibody status was available for 1,315 of the patient samples; $63 \%$ of these were RF positive and $61 \%$ were anti-CCP positive.

\section{Genotyping}

Assay design, validation and genotyping were performed by Kbiosciences (London, UK) using a fluorescence resonance energy transfer based competitive allele-specific polymerase chain reaction system (KASPar).

Of the selected 67 SNPs, 51 were successfully turned into assays. Six SNPs failed to make good assays (rs1049255 [CYBA], rs699244, rs789180, rs4652813 and rs6667363 [NCF2], and rs2075938 [NCF4]), whereas 10 were monomorphic in the panel of 40 Caucasians used for validation or in the EIRA cohort (rs1804006 [CYBA], rs789183, rs 13306581 and rs13306575 [NCF2], and rs13057803, rs1003501, rs12158689, rs9610595, rs2072706 and rs2072711 [NCF4]; Additional file 1). Fourteen of the SNPs were genotyped in all available samples $(1,842$ cases and 1,038 controls), whereas the other 37 SNPs were genotyped in a subset of the samples comprising 1,069 patients and 634 controls (Additional file 1).

\section{Hardy-Weinberg analysis}

The Haploview software calculates $P$ values for deviations from Hardy-Weinberg equilibrium (HWE) for each marker on the complete uploaded dataset [34]. A significance threshold of $P \leq 0.001$ was used. In order to obtain HWE $P$ values for the case and control groups separately, each dataset was uploaded separately.

\section{Single marker analysis}

Contingency tables were created for each SNP using the JMP 5.0 software (SAS Institute, Cary, NC, USA), and $P$ values for association with RA were calculated using $\chi^{2}$ tests for genotype frequencies. The sample set was stratified for sex in the initial analysis, and for sex and RF or anti-CCP status in the stratified analysis. Because CYBB is located on the $\mathrm{X}$ chromosome, allele frequencies were used to estimate association in the male samples.

To obtain a corrected $\alpha$ level in the stratified analysis, the Bonferroni correction method was applied, as implemented on the simple interactive statistical analysis website [35].

We also performed logistic regression analysis for the rs729749 SNP, in order to adjust for age, sex and living area. Logistic regression analysis was conducted for a subset of the material, in which all information regarding genetic factors, antibodies and matching variables was available. This same sample set was used for the frequency analysis of rs729749. We used the SAS software for Windows (version 9.1; SAS Institute, Cary, NC, USA) to perform logistic regression analysis.

\section{Haplotype analysis}

Haplotype blocks were calculated using Haploview [34]. SNPs that departed from HWE in both cases and controls were excluded from the analysis. The haplotype predictions were based on the $\mathrm{Cl}$ method proposed by Gabriel and coworkers [36]. However, the other available methods yielded the same result. Haplotypes were assessed using the WHAP software [37]. Sub-haplotypes were investigated for associations based on the block structure predicted in Haploview. Because the haplotype block analysis is based on all genotyped SNPs, we used only the genotype information from the subset of the EIRA cohort comprising 1,069 cases and 634 controls. The permuted $P$ values for the haplotypes are based on 5,000 permutations.

\section{Genome analysis}

The region surrounding rs729749 was investigated for the presence of regulatory elements, transcription factor binding sites and conserved regions using the University of California, Santa Cruz (UCSC) Genome Browser [38]. The ESPERR Regulatory potential (seven species), Conservation, and TFBS Conservation options were used.

$P$ values and odds ratios (OR) with 95\% Cls for the genetic models were calculated using the GraphPad Prism software (GraphPad Software, San Diego, CA, USA).

\section{Results \\ Fifty-one single nucleotide polymorphisms were successfully genotyped in a Swedish rheumatoid arthritis cohort}

To investigate the genes in the NOX complex for association with RA, 67 SNPs evenly dispersed in the five candidate genes (Table 1) were selected from the HapMap genome browser and dbSNP (National Center for Biotechnology Information; Additional file 1). Fifty-one out of the 67 SNPs were successfully assayed and genotyped in the Swedish EIRA cohort $[39,40]$, with a $98 \%$ call rate (Additional file 1). Deviations from HWE were estimated for each SNP in all samples combined and in cases and controls separately. The SNP rs3788524 (NCF4) significantly deviated from HWE $(P<$ $0.001)$ in both the case and control groups, indicating a possible genotype failure.

\section{Genotype analysis indicates male-specific associations with rheumatoid arthritis in NCF2, NCF4 and RAC2}

To evaluate the SNPs for association with RA, contingency tables were created for genotype frequencies and $P$ values were calculated using $\chi^{2}$ tests. Because RA is more frequent in women than in men, the disease mechanisms might be sex 
Table 1

\begin{tabular}{|c|c|c|c|}
\hline Gene & Chromosome & Position & Exons $(n)$ \\
\hline NCF2 & 1 & $181,791,321$ to $181,826,339$ & 15 \\
\hline NCF4 & 22 & $35,586,991$ to $35,604,004$ & 10 \\
\hline CYBB & $\mathrm{x}$ & $37,524,264$ to $37,557,658$ & 13 \\
\hline CYBA & 16 & $87,237,199$ to $87,244,958$ & 6 \\
\hline RAC2 & 22 & $35,951,258$ to $35,970,251$ & 7 \\
\hline
\end{tabular}

Positions according to National Center for Biotechnology Information build 36.1 from the University of California, Santa Cruz genome browser.

dependent. The samples were therefore analyzed either all together or stratified by sex. The initial cut-off $P$ value for significance was set at 0.05 to reduce the risk for missing subgroup-specific associations, which would be weak in the complete sample set. Three SNPs fulfilled this criterion for association with RA, all in men; rs789181 in NCF2 ( $P=0.03)$, rs729749 in NCF4 $(P=0.001)$ and rs1476002 in RAC2 $(P$ $=0.05 ;$ Table 2).

\section{Stratification based on autoantibody status reveals a highly significant association of rs729749 with rheumatoid factor negative rheumatoid arthritis in men}

Because RA is a heterogeneous disease, it is likely that the disease contributing genes differ in different subgroups of patients. Presence or absence of autoantibodies such as RF and anti-CCP antibodies might reflect different underlying disease mechanisms. In order to determine whether the detected associations are specific for a subclass of RA, we stratified the male cases by RF or anti-CCP antibody status and performed an analysis on genotype frequencies for the associated SNPs.

We found the SNPs rs789181 (NCF2) and rs1476002 (RAC2) to be significantly associated in RF-positive men $(P=$ 0.03 and 0.02 , respectively). The SNP rs1476002 was also significantly associated in anti-CCP antibody positive men $(P$ $=0.05)$. However, the $P$ values are only slightly improved com- pared with the initial analysis, suggesting that the associations are not specific for any of these subgroups. On the other hand, the association for rs729749 in NCF4 is highly significant in RF-negative men $(P=0.0002)$, whereas no association was detected in RF-positive men ( $P=0.0713$; Table 3 ). Furthermore, a comparison of the frequencies in RF-negative against RF-positive men also yielded a significant association with RFnegative disease $(P=0.01)$. We also detected a weaker association in anti-CCP antibody negative men $(P=0.003$; Table $3)$, although the anti-CCP antibody negative versus anti-CCP antibody positive comparison is not significant $(P=0.08)$. Logistic regression analysis of the CT or TT genotype against the CC genotype, adjusted for age and residential area, also indicated a sex and subgroup specific effect for rs729749 (Table 4). With regard to RF-negative RA among men, the OR for CT against $\mathrm{CC}$ is $0.34(95 \% \mathrm{Cl}=0.20$ to $0.60 ; P=$ $0.0001)$. Here we also see a strong association in anti-CCP antibody negative men $(\mathrm{OR}=0.4,95 \% \mathrm{Cl}=0.2$ to $0.7 ; P=$ 0.0004).

To determine the validity of the $P$ value, we estimated a corrected $\alpha$ value using the Bonferroni correction method. The corrected $\alpha$ level for the number of tests performed (159) was estimated at 0.0003 . Hence, only the association detected for rs729749 in RF-negative males remained significant using the corrected $\alpha$ level.

Table 2

Associated SNPs in the initial genotype analysis

\begin{tabular}{|c|c|c|c|c|c|c|}
\hline SNP id & Case/control & & Genotype & & Sex & $P$ \\
\hline \multirow[t]{2}{*}{ rs729749 } & Case & CC 0.69 (256) & СТ 0.26 (95) & TT 0.05 (18) & Male & 0.001 \\
\hline & Control & CC 0.57 (141) & CT 0.40 (98) & TT 0.04 (9) & & \\
\hline \multirow[t]{2}{*}{ rs789181 } & Case & AA $0.81(244)$ & AG 0.15 (46) & GG $0.03(10)$ & Male & 0.03 \\
\hline & Control & AA 0.78 (146) & AG $0.22(41)$ & GG 0.005 (1) & & \\
\hline \multirow[t]{2}{*}{ rs1476002 } & Case & CC 0.77 (395) & СТ 0.22 (115) & TT 0.01 (6) & Male & 0.05 \\
\hline & Control & CC 0.76 (229) & CT $0.20(61)$ & TT 0.04 (11) & & \\
\hline
\end{tabular}

SNP, single nucleotide polymorphism. Values indicate the genotype frequencies and number (in brackets). 
Table 3

\begin{tabular}{|c|c|c|c|c|c|}
\hline \multirow[t]{2}{*}{ Antibody status } & \multirow[t]{2}{*}{ Case/control } & \multicolumn{3}{|c|}{ Genotypes } & \multirow[t]{2}{*}{$P$} \\
\hline & & $\mathrm{CC}$ & СТ & TT & \\
\hline \multirow[t]{2}{*}{ RF positive } & Case & $0.68(169)$ & $0.29(71)$ & $0.03(7)$ & 0.0713 \\
\hline & Control & $0.58(170)$ & $0.37(108)$ & $0.04(11)$ & \\
\hline \multirow[t]{2}{*}{ RF negative } & Case & $0.71(87)$ & $0.20(24)$ & $0.09(11)$ & 0.0002 \\
\hline & Control & $0.57(141)$ & $0.40(98)$ & $0.04(9)$ & \\
\hline \multirow[t]{2}{*}{ Anti-CCP positive } & Case & 0.69 (159) & $0.28(63)$ & $0.03(7)$ & 0.0398 \\
\hline & Control & $0.59(167)$ & $0.38(107)$ & $0.04(11)$ & \\
\hline \multirow[t]{2}{*}{ Anti-CCP negative } & Case & $0.70(97)$ & $0.22(31)$ & $0.08(11)$ & 0.0032 \\
\hline & Control & $0.59(167)$ & $0.38(107)$ & $0.04(11)$ & \\
\hline
\end{tabular}

$\mathrm{CCP}$, cyclic citrullinated peptide; RF, rheumatoid factor. Values indicate the genotype frequencies and number (in brackets).

Haplotype analysis reveals an associated haplotype in NCF4 caused by the rs729749 single nucleotide polymorphism

We wished to estimate haplotypes and haplotype blocks to determine whether rs729749 is included in a conserved and possibly associated haplotype. The Haploview software was used to determine the haplotype block structures of the genes. The analysis showed that the NCF4 gene is divided into three blocks (Figure 1). One block of 1 kilobase contains rs729749 as well as three other genotyped SNPs: rs760519, rs2284027 and rs17811059. To test the association of the haplotype blocks, we used the WHAP software. The block containing rs729749 is borderline significant in the nonstratified analysis $(P=0.055)$, but excluding rs2284027 and rs17811059 yields a significant association (empirical $P=$ 0.04 in all and 0.03 in men; Table 5). In order to determine how

Table 4

Logistic regression analysis of rs729749 in cases stratified for autoantibody status

\begin{tabular}{|c|c|c|c|c|c|c|c|}
\hline \multirow[t]{2}{*}{ Status } & \multirow[t]{2}{*}{ Subgroup } & \multicolumn{3}{|c|}{ Genotype CT versus CC } & \multicolumn{3}{|c|}{ Genotype TT versus CC } \\
\hline & & OR & $95 \% \mathrm{Cl}$ & $P$ & OR & $95 \% \mathrm{Cl}$ & $P$ \\
\hline \multirow[t]{3}{*}{ All } & All & 0.80 & 0.66 to 0.97 & 0.02 & 1.04 & 0.67 to 1.62 & 0.86 \\
\hline & Women & 0.94 & 0.75 to 1.17 & 0.56 & 1.01 & 0.60 to 1.71 & 0.97 \\
\hline & Men & 0.50 & 0.35 to 0.73 & 0.0002 & 1.20 & 0.52 to 2.81 & 0.67 \\
\hline \multirow[t]{3}{*}{ RF positive } & All & 0.85 & 0.69 to 1.04 & 0.12 & 0.92 & 0.56 to 1.53 & 0.76 \\
\hline & Women & 0.96 & 0.75 to 1.23 & 0.74 & 1.03 & 0.58 to 1.84 & 0.92 \\
\hline & Men & 0.59 & 0.39 to 0.88 & 0.009 & 0.74 & 0.26 to 2.12 & 0.58 \\
\hline \multirow[t]{3}{*}{ RF negative } & All & 0.70 & 0.54 to 0.90 & 0.006 & 1.24 & 0.71 to 2.14 & 0.45 \\
\hline & Women & 0.88 & 0.65 to 1.18 & 0.39 & 0.94 & 0.47 to 1.90 & 0.87 \\
\hline & Men & 0.34 & 0.20 to 0.60 & 0.0001 & 2.03 & 0.88 to 5.29 & 0.15 \\
\hline \multirow[t]{3}{*}{ Anti-CCP positive } & All & 0.86 & 0.70 to 1.07 & 0.17 & 1.01 & 0.61 to 1.71 & 0.98 \\
\hline & Women & 1.02 & 0.80 to 1.31 & 0.88 & 1.12 & 0.63 to 2.00 & 0.70 \\
\hline & Men & 0.54 & 0.36 to 0.83 & 0.003 & 0.79 & 0.28 to 2.24 & 0.65 \\
\hline \multirow[t]{3}{*}{ Anti-CCP negative } & All & 0.69 & 0.54 to 0.89 & 0.004 & 1.07 & 0.62 to 1.84 & 0.82 \\
\hline & Women & 0.82 & 0.61 to 1.10 & 0.19 & 0.86 & 0.43 to 1.73 & 0.67 \\
\hline & Men & 0.4 & 0.2 to 0.7 & 0.0004 & 1.8 & 0.7 to 4.6 & 0.26 \\
\hline
\end{tabular}

$\mathrm{CCP}$, cyclic citrullinated peptide; $\mathrm{Cl}$, confidence interval; OR, odds ratio; $\mathrm{RF}$, rheumatoid factor. 
important the impact of the rs729749 SNP is for the identified associated haplotype, we conducted a conditional analysis in which the association of the haplotype was estimated while controlling for the haplotype background of rs760519 and rs2284027. This test gave an empirical $P$ value of 0.01 , which is lower than for the associated haplotype, indicating that the rs729749 SNP itself or a SNP in strong linkage disequilibrium is causing the haplotype association.

\section{Homozygosity could explain the genetic risk associated with rs729749}

The rs726749 SNP is noncoding and located in the beginning of intron 4 in NCF4. Analysis of the region using the UCSC genome browser (March 2006 assembly) [38] revealed that it is not located at any known transcription factor binding site or regulatory element; however, there is a conserved regulatory region (as predicted by the ESPERR regulatory potential option) approximately 300 base pairs downstream of rs729749. Nonetheless, the genetic effect of this SNP is not obvious.

By looking at the genotype frequencies in RF-negative males for rs729749, it appears as though both homozygous genotypes are more common in the RA patients (Table 3 ). This led us to perform an analysis to determine which genetic model best fits the data. Not surprisingly, the homozygous model (CC + TT versus $\mathrm{CT}$ ) gave the best fit in the subgroup of RFnegative men $(\mathrm{OR}=2.67,95 \% \mathrm{Cl}=1.60$ to $4.46 ; P=$ 0.0002 ; Table 6). However, because the allele frequency of the T-allele is quite low and few individuals are homozygous for this allele, there is a degree of uncertainty in this prediction. The CC genotype is clearly more common in the patients and homozygosity at this locus also gives a significant genetic model (Table 6).

\section{Discussion}

Here we report an association of the SNP rs729749, located in the gene NCF4, with RA in Swedish RF/anti-CCP antibody negative male patients. NCF4 is part of the NOX complex, and

Table 5

\begin{tabular}{|c|c|c|c|c|}
\hline \multirow[t]{2}{*}{ Haplotype $^{\mathrm{a}}$} & \multicolumn{2}{|c|}{ Frequency } & \multirow[t]{2}{*}{ Subgroup } & \multirow{2}{*}{$\begin{array}{l}\text { Empirica } \\
P^{b}\end{array}$} \\
\hline & Cases & Controls & & \\
\hline $\mathrm{TC}$ & 0.82 & 0.80 & - & 0.038 \\
\hline CT & 0.15 & 0.16 & & \\
\hline TT & 0.04 & 0.05 & & \\
\hline $\mathrm{TC}$ & 0.81 & 0.77 & men & 0.029 \\
\hline CT & 0.15 & 0.17 & & \\
\hline TT & 0.03 & 0.06 & & \\
\hline
\end{tabular}

a Haplotype of rs760519 and rs729749. bBased on 5,000 permutations. our results support recent findings that ROS play a role in the development of RA. However, because this is the first report of an association between a gene in the NOX complex and $\mathrm{RA}$, genetic replication as well as functional studies will be required before it is possible to determine conclusively whether NCF4 is an RA susceptibility gene. Furthermore, the results from this study do not exclude the possibility that the other genes in the NOX complex could affect RA susceptibility. There could, for example, be epistatic effects between the different genes in the complex.

There is a lack of consensus in the field about statistical significance levels in association studies. In this study we initially used an $\alpha$ level of 0.05 to reduce the risk for overlooking associations that are specific for a subgroup of RA patients. There are strong medical and biological arguments in favour of subgrouping RA patients, and an analysis of nonstratified samples might conceal a true association. In the initial analysis of the genotype frequencies we found indications of association with three SNPs, and stratification of the samples indicates that the association for rs729749 is male specific and predominates in RF-negative disease. We also found a weaker association in anti-CCP antibody negative disease, but at this stage it is not possible to say whether this is due to the fact that the presence of RFs and anti-CCP antibodies is dependent [41] or whether the anti-CCP antibodies independently influence genetic risk.

The detected association of rs729749 is strongest in RF-negative males, and therefore it is possible that this particular SNP modulates the affected disease pathway so that it mainly influences the clinical disease in RF-negative RA, specifically in men. However, it is not impossible that this pathway play a role also in other subtypes of RA. The results from this study strengthen the view that different combinations of genes are involved in the disease progression in different RA subclasses defined, for instance, by sex or autoantibody status. The most striking aspect of the identified association of the rs729749 SNP is the clear sex specificity, indicating that the disease pathway affected by the rs729749 SNP is specific to men. The fact that RA is three times more common in women than in men suggests that men and women respond differently to factors that trigger the onset of RA and that some disease pathways could be sex specific. The RF-negative specificity of the association is not as striking as the sex specificity, but it might still point toward which RA subgroup is affected by the rs729749 SNP. Because both RFs and anti-CCP antibodies can be detected before the appearance of any disease symptoms [7,42], they might reflect or be part of initial disease mechanisms that are only present in anti-CCP antibody or RF positive patients. Furthermore, it has repeatedly been shown that patients who are negative for these autoantibodies have a less severe disease outcome than do anti-CCP antibody or RF positive RA patients [10-12]. This further supports the view that autoantibody negative RA is another variant of RA. Also, 


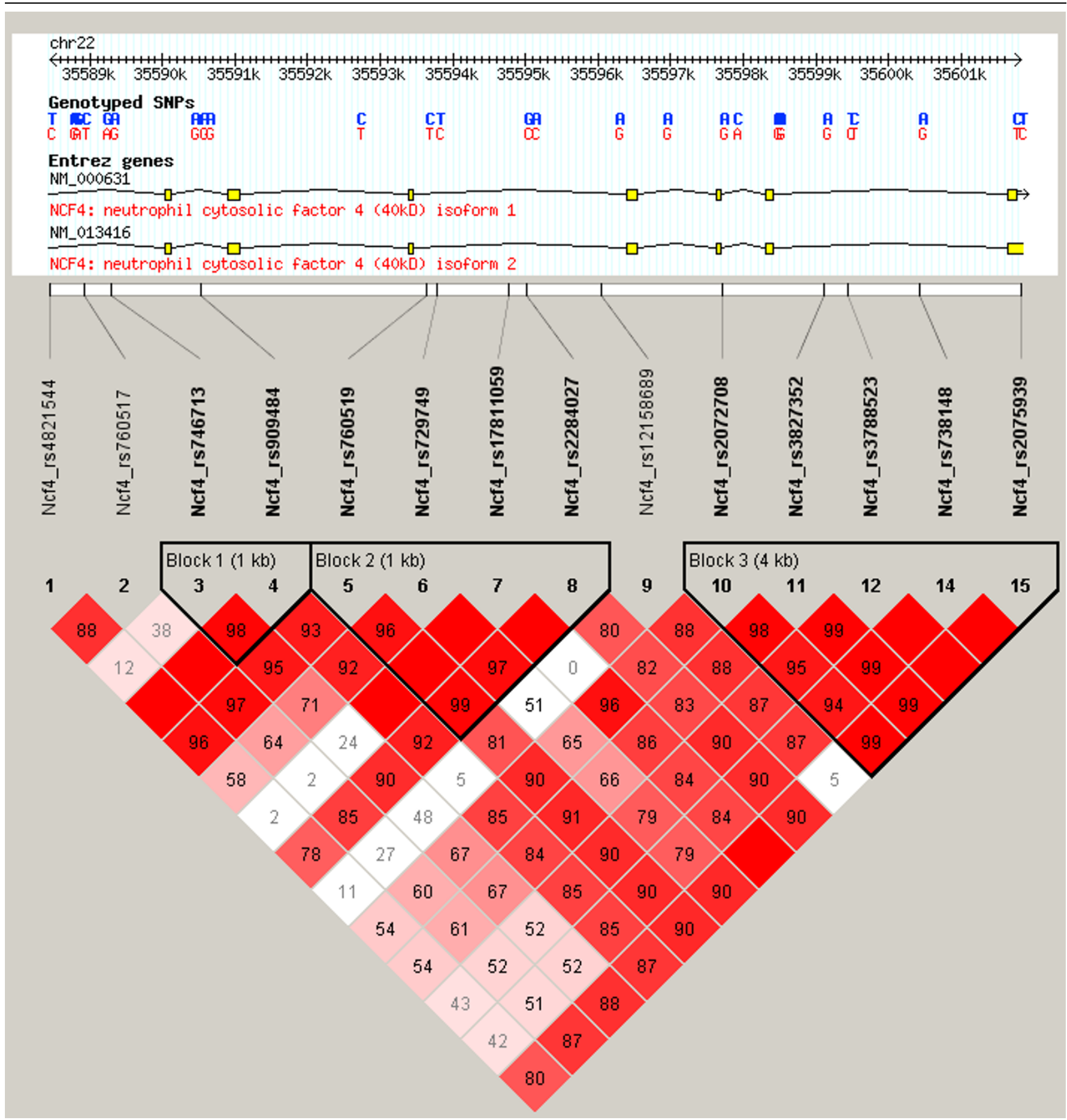

Haplotype blocks in NCF4. Three haplotype blocks were identified in NCF4. Block 2 contains the associated single nucleotide polymorphism (SNP) rs729749. Colour scheme of the linakge disequilibrium LD map is based on the standard D'/LOD option in the Haploview software. The LD blocks are calculated based on the $\mathrm{Cl}$ method.

the few genes confirmed to be associated with RA have been shown mainly to affect subclasses of RA.

The well established association of the HLA-DRB1 alleles, which encode the so-called shared epitope (SE), was recently suggested to be restricted to anti-CCP antibody but not RF positive RA $[15,16,41]$. However, it has also been shown that SE alleles are associated with higher titres of autoantibodies against type II collagen [43]. Interestingly, the $H L A-D R 3$ locus, which does not encode the SE, appears to be associated only 
Table 6

Genetic models of rs729749 in RF negative males

\begin{tabular}{llllll}
\hline \multirow{2}{*}{ Model } & \multicolumn{2}{c}{ Frequency of risk variant } & OR & 95\% Cl & \\
\cline { 2 - 4 } & Cases & Controls & & & \\
\hline CC + TT versus CT & 0.80 & 0.60 & 2.67 & 1.60 to 4.46 & 0.0002 \\
CC versus CT & 0.71 & 0.57 & 2.52 & 1.50 to 4.24 & 0.0004 \\
TT versus CT & 0.09 & 0.04 & 4.99 & 1.86 to 13.4 & 0.0016 \\
CC versus CT + TT & 0.71 & 0.57 & 1.89 & 1.18 to 3.01 & 0.0088 \\
TT versus CC + CT & 0.09 & 0.04 & 2.63 & 1.06 to 6.53 & 0.0476 \\
\hline
\end{tabular}

$\mathrm{Cl}$, confidence interval; OR, odds ratio; RF, rheumatoid factor.

with anti-CCP negative RA $[41,44]$. The recently discovered PTPN22 risk allele has been shown to be associated with both RF and anti-CCP antibody positive RA $[43,45,46]$, but there are conflicting data regarding the autoantibody restriction of this association [47]. Furthermore, the reported association of the PD-1.2A allele of the PDCD1 gene is restricted to RF negative as well as SE negative RA [48]. Hence, even though little is known about the precise disease mechanisms in RA, it is obvious that the symptoms can be caused by several different distinct disease pathways.

Because of the lack of certain autoantibodies, it is tempting to speculate that RF or anti-CCP antibody negative RA patients have a lesser $B$-cell component, and reports indicating that $B$ cell depleting therapy is a less effective treatment for RF-negative RA supports such a view $[49,50]$. Several recent clinical studies, however, have yielded conflicting results on B-cell depletion efficiency [51], and more extensive studies are required before any conclusions can be drawn about the $B$ cell dependence in RF and anti-CCP antibody negative RA. In addition, it is fair to assume that the autoantibody negative forms of RA, in themselves, represent a heterogeneous collection of pathways related, for example, to osteoarthritis, arthropathies, or lupus.

The rodent arthritis models are heterogeneous as well but they may relate to more defined arthritis conditions than the human disease. Interestingly, the pristane-induced arthritis model used to identify the polymorphism in Ncf1 in rats is B-cell independent. Studies have shown that transfer of T-cells from genetically susceptible and immunized rats into genetically resistant and un-immunized rats is enough to induce arthritis in the resistant rat [52].

Both the HLA-DRB1 locus and PTPN22 are believed to affect T-cell activation. $H L A-D R B 1$ is expressed by antigen-presenting cells and restricts the presentation of antigens to $T$ cells. PTPN22 on the other hand has an intracellular effect, and the amino acid shift to the disease-associated tryptophan impairs the function of the Lyp protein, encoded by PTPN22, rendering it a less potent negative regulator of T-cell activation [53].
Studies in animal models as well as recent findings suggest that the NOX complex could also be involved in T-cell activation [29,54]. ROS production has been found in antigen-presenting cells, and it has also been shown that T-cell receptor signalling is affected by oxidation of the T-cell membrane as well as by intracellular levels of ROS $[55,56]$. Interestingly, hydrogen peroxide generated from ${ }^{\circ} \mathrm{O}_{2}$ - produced by the NOX complex can readily cross the cell membrane and inactivate protein tyrosine phosphatases, including that encoded by PTPN22, through oxidation of a specific cysteine residue [54]. ROS production of antigen-presenting cells, such as dendritic cells, has been found to be crucial for the activation of T-cells [28] and could therefore determine the immune response to an antigen. Furthermore, recent work from our group highlights the importance of the redox balance on the surface of $T$ cells for activation. T-cells originating from the Ncf1 mutated rat DA have an increased number of reduced thiol groups on the cell surface, which increases proliferation and activation [29]. Gelderman and coworkers [29] showed that T-cells originating from the nonmutated E3 rats could be made arthritogenic by increasing the number of reduced thiol groups on the cell surface. Because NOX production could not be detected in Tcells, it was concluded that the redox balance of T-cell surfaces is determined by other cells, such as macrophages or dendritic cells.

In the rat a clear difference in the capacity to produce oxidative burst is the result of a single SNP in Ncf1, resulting in the shift from threonine to the disease-promoting methionine at position 153 in the p47phox protein [21]. The consequences of the amino acid shift have not yet been identified, although position 153 does not coincide with any critical binding sites. It is most likely that the shift affects the three-dimensional structure of the protein, impairing the binding capabilities to the other proteins in the complex. The activation of the NOX complex is initiated through phosphorylation of the three cytoplasmic proteins p47phox (NCF1), p67phox (NCF2) and p40phox (NCF4) $[23,26,57]$. The phosphorylations lead to conformational changes of p47phox, and subsequent translocation of the three proteins to the membrane, where it interacts with and activates the membrane bound complex flavocytochrome $b_{558}$, which is 
composed of gp91phox (CYBB) and p22phox (CYBA) [24,58]. $R A C 2$ also translocates to the membrane after dissociation from Rho-guanine nucleotide dissociation inhibitor and interacts with flavocytochrome $b_{558}[23,59]$. Studies show that p67phox and Rac2 are critical for the function of the complex $[25,60]$, whereas $\mathrm{p} 40^{\mathrm{phox}}$ and $\mathrm{p} 47^{\mathrm{phox}}$ function as adaptor proteins and are responsible for the assembly of the complex [61]. The precise role of $\mathrm{p} 40^{p h o x}$ is still debated, and there is evidence of both positive and negative regulation of the NOX complex [61-63]. Recent studies have suggested that p40phox, as well as p47phox, functions by 'carrying' p67phox to the membrane through the interaction with phospholipids $[62,64]$. Studies of mutations causing human chronic granulomatous disease show that mutations in NCF1, CYBB, CYBA, or NCF2 lead to a complete lack of function of the NOX complex $[65,66]$. However, SNPs in less critical regions, like the 153 SNP in Ncf1 found in rat, apparently reduce but do not completely abolish ROS production, which leads to an increased susceptibility to arthritis [21]. These facts indicate that the SNPs of interest for examination in an RA association study of the NOX complex will probably be located at noncritical positions and will not completely abolish but only slightly modify binding to the other proteins.

The rs729749 SNP is located in the middle part of intron 4 in NCF4. By studying the genome maps using the UCSC genome browser, we could not find any evidence of it affecting a transcription factor binding site or a known regulatory element. However, there is a conserved regulatory region predicted approximately 300 base pairs downstream of rs729749. The haplotype analysis indicates that rs729749, or a SNP in very high LD, is responsible for the association detected for the haplotype. Also, because the predicted regulatory region is very close to rs729749, it could very well contain the causative SNP.

The genetic analysis of the association shows that the homozygous model gives the best significance, indicating that this could be the genetic effect. However, the low number of samples in the subgroup of RF-negative males together with the low frequency of the $T$ allele make this assumption somewhat uncertain. Furthermore, it is not obvious what the functional consequences of a homozygous effect would be. We therefore chose to present all models tested in order to provide the full picture.

In the logistic regression analysis, weak associations were also detected for RF and anti-CCP antibody positive disease. One possible explanation for these findings is that some patients could have been 'misdiagnosed' regarding autoantibody status. The diagnosis is made by measuring the autoantibody titres, and certain threshold are used to determine positive versus negative status. However, sometimes autoantibody status changes as the disease progresses, and therefore there is a degree of uncertainty regarding autoantibody status.
A method or a strategy to apply multiple testing corrections accurately in a case-control candidate gene association study has not yet been established $[67,68]$. The conventional multiple correction methods, such as Bonferroni, are considered by some to be too stringent for large-scale studies $[69,70]$. The Bonferroni correction method is used to correct for the number of independent tests performed. However, in an association analysis neither the SNPs tested nor the different stratified analyses are truly independent. The allele frequencies of the SNPs are affected by the LD of the region, and the stratified analyses are based on the same SNPs and samples as the initial analysis and can therefore not be considered to be independent from each other. Nonetheless, in order to obtain an indication of the validity of the $P$ values obtained in these analyses, we used the Bonferroni correction method to estimate an $\alpha$ level correcting for the number of tests (159) performed in the frequency analysis. The 159 tests reflect the sex-stratified analysis of all 51 SNPs (153) plus the stratified analysis of RF and anti-CCP antibody status performed for rs729749, rs789181 and rs1476002 in the male subset (6). Correcting for 159 tests gives a new $\alpha$ level of 0.0003 , which means that only the association of rs729749 in RF-negative males passed the significance threshold using this stringent method.

The EIRA study included mainly individuals born in Sweden. Taking those born outside Sweden into consideration also, $97 \%$ were of Caucasian origin. In order to minimize potential bias resulting from population stratification, we performed logistic regression analyses in which ORs were adjusted for age and residential area.

\section{Conclusion}

We found evidence of an RA-associated SNP in the NCF4 gene of the NOX complex. The association is specific for male patients, with the strongest association found in RF-negative RA. This finding supports the notion of RA being a heterogeneous disease caused by a variety of disease pathways that are regulated by a variety of contributing risk genes. The detected association with a component of the NOX complex also strengthens previous evidence obtained in animal models that suggests that the NOX complex and ROS have a major impact on inflammation and autoimmunity. It is hoped that this finding will help to elucidate the complex genetics that underlie RA and autoimmunity.

\section{Competing interests}

The authors declare that they have no competing interests.

\section{Authors' contributions}

LMO has been the responsible investigator for the project and has carried out SNP selection, genotype preparation, statistical analyses and drafted the manuscript. A-KL participated in the design of the study and the statistical analyses. HK and LA performed the logistic regression analysis. LP and LK were responsible for the distribution of the EIRA cohort. HB has 
contributed with intellectual property to the study. $\mathrm{RH}$ conceived of the study, participated in its design and helped to draft the manuscript.

\section{Additional files}

The following Additional files are available online:

\section{Additional file 1}

An Word file containing a table that shows a table of all SNPs evaluated for association with RA in this study. See http://www.biomedcentral.com/content/ supplementary/ar2299-S1.doc

\section{Acknowledgements}

This work was supported by the Swedish Research Council, the Strategic Science foundation, the Foundations of Craaford, Kock, Österlunds and the European Union Grants Autocure (LSHB-2006-018661) and Neuropromise (LSHM-LT-018637).

\section{References}

1. Seldin MF, Amos Cl, Ward R, Gregersen PK: The genetics revolution and the assault on rheumatoid arthritis. Arthritis Rheum 1999, 42:1071-1079.

2. Gregersen PK, Silver J, Winchester RJ: The shared epitope hypothesis. An approach to understanding the molecular genetics of susceptibility to rheumatoid arthritis. Arthritis Rheum 1987, 30:1205-1213.

3. Weyand CM, Goronzy JJ: Association of MHC and rheumatoid arthritis. HLA polymorphisms in phenotypic variants of rheumatoid arthritis. Arthritis Res 2000, 2:212-216.

4. Begovich AB, Carlton VE, Honigberg LA, Schrodi SJ, Chokkalingam AP, Alexander HC, Ardlie KG, Huang Q, Smith AM, Spoerke $\mathrm{JM}$, et al:: A missense single-nucleotide polymorphism in a gene encoding a protein tyrosine phosphatase (PTPN22) is associated with rheumatoid arthritis. Am J Hum Genet 2004, 75:330-337.

5. Arnett FC, Edworthy SM, Bloch DA, McShane DJ, Fries JF, Cooper NS, Healey LA, Kaplan SR, Liang MH, Luthra HS, et al: : The American Rheumatism Association 1987 revised criteria for the classification of rheumatoid arthritis. Arthritis Rheum 1988, 31:315-324.

6. Schellekens $G A$, Visser $H$, de Jong $B A$, van den Hoogen $F H$, Hazes JM, Breedveld FC, van Venrooij WJ: The diagnostic properties of rheumatoid arthritis antibodies recognizing a cyclic citrullinated peptide. Arthritis Rheum 2000, 43:155-163.

7. Rantapaa-Dahlqvist $S$, de Jong BA, Berglin E, Hallmans $G$, Wadell G, Stenlund H, Sundin U, van Venrooij WJ: Antibodies against cyclic citrullinated peptide and IgA rheumatoid factor predict the development of rheumatoid arthritis. Arthritis Rheum 2003, 48:2741-2749.

8. van Gaalen FA, Linn-Rasker SP, van Venrooij WJ, de Jong BA, Breedveld FC, Verweij CL, Toes RE, Huizinga TW: Autoantibodies to cyclic citrullinated peptides predict progression to rheumatoid arthritis in patients with undifferentiated arthritis: a prospective cohort study. Arthritis Rheum 2004, 50:709-715.

9. Dorner T, Egerer K, Feist E, Burmester GR: Rheumatoid factor revisited. Curr Opin Rheumatol 2004, 16:246-253.

10. Turesson C, Jacobsson LT, Sturfelt G, Matteson EL, Mathsson L, Ronnelid J: Rheumatoid factor and antibodies to cyclic citrullinated peptides are associated with severe extra-articular manifestations in rheumatoid arthritis. Ann Rheum Dis 2007, 66:59-64.

11. Mewar D, Coote A, Moore DJ, Marinou I, Keyworth J, Dickson MC, Montgomery DS, Binks MH, Wilson AG: Independent associations of anti-cyclic citrullinated peptide antibodies and rheu- matoid factor with radiographic severity of rheumatoid arthritis. Arthritis Res Ther 2006, 8:R128.

12. van der Helm-van Mil AH, Verpoort KN, Breedveld FC, Toes RE Huizinga TW: Antibodies to citrullinated proteins and differences in clinical progression of rheumatoid arthritis. Arthritis Res Ther 2005, 7:R949-R958.

13. Meyer O, Labarre C, Dougados M, Goupille P, Cantagrel A Dubois A, Nicaise-Roland P, Sibilia J, Combe B: Anticitrullinated protein/peptide antibody assays in early rheumatoid arthritis for predicting five year radiographic damage. Ann Rheum Dis 2003, 62:120-126.

14. Vencovsky J, Machacek S, Sedova L, Kafkova J, Gatterova J, Pesakova V, Ruzickova S: Autoantibodies can be prognostic markers of an erosive disease in early rheumatoid arthritis. Ann Rheum Dis 2003, 62:427-430.

15. van der Helm-van Mil AH, Verpoort KN, Breedveld FC, Huizinga TW, Toes RE, de Vries RR: The HLA-DRB1 shared epitope alleles are primarily a risk factor for anti-cyclic citrullinated peptide antibodies and are not an independent risk factor for development of rheumatoid arthritis. Arthritis Rheum 2006, 54:1117-1121.

16. Klareskog L, Stolt P, Lundberg K, Kallberg H, Bengtsson C, Grunewald J, Ronnelid J, Harris HE, Ulfgren AK, Rantapaa-Dahlqvist S, et al.: A new model for an etiology of rheumatoid arthritis: smoking may trigger HLA-DR (shared epitope)-restricted immune reactions to autoantigens modified by citrullination. Arthritis Rheum 2006, 54:38-46.

17. van der Helm-van Mil AH, Verpoort KN, le Cessie S, Huizinga TW, de Vries RR, Toes RE: The HLA-DRB1 shared epitope alleles differ in the interaction with smoking and predisposition to antibodies to cyclic citrullinated peptide. Arthritis Rheum 2007, 56:425-432.

18. Hirschhorn JN, Daly MJ: Genome-wide association studies for common diseases and complex traits. Nat Rev Genet 2005 , 6:95-108.

19. Freimer N, Sabatti C: The use of pedigree, sib-pair and association studies of common diseases for genetic mapping and epidemiology. Nat Genet 2004, 36:1045-1051.

20. Olofsson P, Holmberg J, Pettersson U, Holmdahl R: Identification and isolation of dominant susceptibility loci for pristaneinduced arthritis. J Immunol 2003, 171:407-416.

21. Olofsson P, Holmberg J, Tordsson J, Lu S, Akerstrom B, Holmdahl $\mathrm{R}$ : Positional identification of $\mathrm{Ncf1}$ as a gene that regulates arthritis severity in rats. Nat Genet 2003, 33:25-32.

22. Hultqvist M, Olofsson P, Holmberg J, Backstrom BT, Tordsson J, Holmdahl R: Enhanced autoimmunity, arthritis, and encephalomyelitis in mice with a reduced oxidative burst due to a mutation in the Ncf1 gene. Proc Natl Acad Sci USA 2004 101:12646-12651.

23. Nauseef WM: Assembly of the phagocyte NADPH oxidase. Histochem Cell Biol 2004, 122:277-291.

24. Groemping $Y$, Rittinger K: Activation and assembly of the NADPH oxidase: a structural perspective. Biochem J 2005, 386:401-416.

25. Bokoch GM, Diebold BA: Current molecular models for NADPH oxidase regulation by Rac GTPase. Blood 2002, 100:2692-2696.

26. Sheppard FR, Kelher MR, Moore EE, McLaughlin NJ, Banerjee A Silliman CC: Structural organization of the neutrophil NADPH oxidase: phosphorylation and translocation during priming and activation. J Leukoc Biol 2005, 78:1025-1042.

27. Vignais PV: The superoxide-generating NADPH oxidase: structural aspects and activation mechanism. Cell Mol Life Sci 2002, 59:1428-1459.

28. Matsue $H$, Edelbaum $D$, Shalhevet $D$, Mizumoto $N$, Yang $C$, Mummert ME, Oeda J, Masayasu H, Takashima A: Generation and function of reactive oxygen species in dendritic cells during antigen presentation. $J$ Immuno/ 2003, 171:3010-3018.

29. Gelderman KA, Hultqvist M, Holmberg J, Olofsson $P$, Holmdahl R: $T$ cell surface redox levels determine $T$ cell reactivity and arthritis susceptibility. Proc Natl Acad Sci USA 2006 103:12831-12836.

30. Antonell A, de Luis O, Domingo-Roura X, Perez-Jurado LA: Evolutionary mechanisms shaping the genomic structure of the Williams-Beuren syndrome chromosomal region at human 7q11.23. Genome Res 2005, 15:1179-1188. 
31. Heyworth PG, Noack D, Cross AR: Identification of a novel NCF1 (p47-phox) pseudogene not containing the signature GT deletion: significance for A47 degrees chronic granulomatous disease carrier detection. Blood 2002, 100:1845-1851.

32. The HapMap Genome browser [http://www.hapmap.org]

33. dbSNP (NCBI) [http://www.ncbi.nlm.nih.gov/SNP]

34. Barrett JC, Fry B, Maller J, Daly MJ: Haploview: analysis and visualization of LD and haplotype maps. Bioinformatics 2005, 21:263-265.

35. Simple Interactive Statistical Analysis [http://www.quantita tiveskills.com/sisa/calculations/bonfer.htm]

36. Gabriel SB, Schaffner SF, Nguyen H, Moore JM, Roy J, Blumenstiel B, Higgins J, DeFelice M, Lochner A, Faggart M, et al.: The structure of haplotype blocks in the human genome. Science 2002, 296:2225-2229.

37. Purcell S, Daly MJ, Sham PC: WHAP: haplotype-based association analysis. Bioinformatics 2007, 23:255-256.

38. The UCSC Genome browser [http://genome.ucsc.edu]

39. Padyukov L, Silva C, Stolt P, Alfredsson L, Klareskog L: A geneenvironment interaction between smoking and shared epitope genes in HLA-DR provides a high risk of seropositive rheumatoid arthritis. Arthritis Rheum 2004, 50:3085-3092.

40. Stolt $P$, Bengtsson $C$, Nordmark B, Lindblad S, Lundberg I, Klareskog L, Alfredsson L: Quantification of the influence of cigarette smoking on rheumatoid arthritis: results from a population based case-control study, using incident cases. Ann Rheum Dis 2003, 62:835-841.

41. Irigoyen P, Lee AT, Wener MH, Li W, Kern M, Batliwalla F, Lum RF, Massarotti E, Weisman M, Bombardier C, et al:: Regulation of anti-cyclic citrullinated peptide antibodies in rheumatoid arthritis: contrasting effects of HLA-DR3 and the shared epitope alleles. Arthritis Rheum 2005, 52:3813-3818.

42. Aho K, Palosuo T, Raunio V, Puska P, Aromaa A, Salonen JT: When does rheumatoid disease start? Arthritis Rheum 1985, 28:485-489.

43. Burkhardt $\mathrm{H}$, Huffmeier $\mathrm{U}$, Spriewald B, Bohm B, Rau R, Kallert S, Engstrom A, Holmdahl R, Reis A: Association between protein tyrosine phosphatase 22 variant R620W in conjunction with the HLA-DRB1 shared epitope and humoral autoimmunity to an immunodominant epitope of cartilage-specific type II collagen in early rheumatoid arthritis. Arthritis Rheum 2006, 54:82-89.

44. Verpoort KN, van Gaalen FA, van der Helm-van Mil AH, Schreuder GM, Breedveld FC, Huizinga TW, de Vries RR, Toes RE: Association of HLA-DR3 with anti-cyclic citrullinated peptide antibody-negative rheumatoid arthritis. Arthritis Rheum 2005, 52:3058-3062.

45. Lee AT, Li W, Liew A, Bombardier C, Weisman M, Massarotti EM, Kent J, Wolfe F, Begovich AB, Gregersen PK: The PTPN22 R620W polymorphism associates with RF positive rheumatoid arthritis in a dose-dependent manner but not with HLA-SE status. Genes Immun 2005, 6:129-133.

46. Michou L, Lasbleiz S, Rat AC, Migliorini P, Balsa A, Westhovens R, Barrera $\mathrm{P}$, Alves $\mathrm{H}$, Pierlot $\mathrm{C}$, Glikmans $\mathrm{E}$, et al.: Linkage proof for PTPN22, a rheumatoid arthritis susceptibility gene and a human autoimmunity gene. Proc Natl Acad Sci USA 2007, 104:1649-1654.

47. Pierer $M$, Kaltenhauser S, Arnold S, Wahle M, Baerwald C, Hantzschel H, Wagner U: Association of PTPN22 1858 singlenucleotide polymorphism with rheumatoid arthritis in a German cohort: higher frequency of the risk allele in male compared to female patients. Arthritis Res Ther 2006, 8:R75.

48. Prokunina L, Castillejo-Lopez C, Öberg F, Gunnarsson I, Berg L, Magnusson V, Brookes AJ, Tentler D, Kristjansdottir H, Grondal G, et al:: A regulatory polymorphism in PDCD1 is associated with susceptibility to systemic lupus erythematosus in humans. Nat Genet 2002, 32:666-669.

49. De Vita S, Zaja F, Sacco S, De Candia A, Fanin R, Ferraccioli G: Efficacy of selective $B$ cell blockade in the treatment of rheumatoid arthritis: evidence for a pathogenetic role of $B$ cells. Arthritis Rheum 2002, 46:2029-2033.

50. Leandro MJ, Edwards JC, Cambridge G: Clinical outcome in $\mathbf{2 2}$ patients with rheumatoid arthritis treated with B lymphocyte depletion. Ann Rheum Dis 2002, 61:883-888

51. Edwards JC, Cambridge G: B-cell targeting in rheumatoid arthritis and other autoimmune diseases. Nat Rev Immunol 2006, 6:394-403.
52. Holmberg J, Tuncel J, Yamada H, Lu S, Olofsson P, Holmdahl R: Pristane, a non-antigenic adjuvant, induces MHC class IIrestricted, arthritogenic T cells in the rat. J Immunol 2006, 176:1172-1179.

53. Bottini N, Musumeci L, Alonso A, Rahmouni S, Nika K, Rostamkhani M, MacMurray J, Meloni GF, Lucarelli P, Pellecchia M, et al:: A functional variant of lymphoid tyrosine phosphatase is associated with type I diabetes. Nat Genet 2004, 36:337-338.

54. Reth $\mathrm{M}$ : Hydrogen peroxide as second messenger in lymphocyte activation. Nat Immuno/ 2002, 3:1129-1134.

55. Sahaf B, Heydari K, Herzenberg LA, Herzenberg LA: Lymphocyte surface thiol levels. Proc Natl Acad Sci USA 2003, 100:4001-4005.

56. Gringhuis SI, Papendrecht-van der Voort EA, Leow A, Nivine Levarht EW, Breedveld FC, Verweij CL: Effect of redox balance alterations on cellular localization of LAT and downstream Tcell receptor signaling pathways. Mol Cell Biol 2002, 22:400-411.

57. Lapouge K, Smith SJ, Groemping Y, Rittinger K: Architecture of the p40-p47-p67phox complex in the resting state of the NADPH oxidase. A central role for p67phox. J Biol Chem 2002, 277:10121-10128.

58. Groemping Y, Lapouge K, Smerdon SJ, Rittinger K: Molecular basis of phosphorylation-induced activation of the NADPH oxidase. Cell 2003, 113:343-355.

59. Heyworth PG, Bohl BP, Bokoch GM, Curnutte JT: Rac translocates independently of the neutrophil NADPH oxidase components p47phox and p67phox. Evidence for its interaction with flavocytochrome b558. J Biol Chem 1994, 269:30749-30752.

60. Nisimoto Y, Ogawa H, Miyano K, Tamura M: Activation of the flavoprotein domain of gp91phox upon interaction with $\mathrm{N}$-terminal p67phox (1-210) and the Rac complex. Biochemistry 2004, 43:9567-9575

61. Kuribayashi F, Nunoi H, Wakamatsu K, Tsunawaki S, Sato K, Ito T, Sumimoto $\mathrm{H}$ : The adaptor protein $\mathrm{p} 40$ (phox) as a positive regulator of the superoxide-producing phagocyte oxidase. Embo J 2002, 21:6312-6320.

62. Ellson C, Davidson K, Anderson K, Stephens LR, Hawkins PT: Ptdlns3P binding to the PX domain of p40phox is a physiological signal in NADPH oxidase activation. Embo J 2006, 25:4468-4478.

63. Lopes LR, Dagher MC, Gutierrez A, Young B, Bouin AP, Fuchs A, Babior BM: Phosphorylated $\mathrm{p} 40 \mathrm{PHOX}$ as a negative regulator of NADPH oxidase. Biochemistry 2004, 43:3723-3730.

64. Ueyama T, Tatsuno T, Kawasaki T, Tsujibe S, Shirai Y, Sumimoto $\mathrm{H}$, Leto $\mathrm{TL}$, Saito N: A regulated adaptor function of p40phox: distinct p67phox membrane targeting by p40phox and by p47phox. Mol Biol Cell 2007, 18:441-454.

65. Cross AR, Noack D, Rae J, Curnutte JT, Heyworth PG: Hematologically important mutations: the autosomal recessive forms of chronic granulomatous disease (first update). Blood Cells Mol Dis 2000, 26:561-565.

66. Heyworth PG, Curnutte JT, Rae J, Noack D, Roos D, van Koppen E, Cross AR: Hematologically important mutations: X-linked chronic granulomatous disease (second update). Blood Cells Mol Dis 2001, 27:16-26.

67. Zondervan KT, Cardon LR: The complex interplay among factors that influence allelic association. Nat Rev Genet 2004, 5:89-100.

68. Gregersen PK: Pathways to gene identification in rheumatoid arthritis: PTPN22 and beyond. Immunol Rev 2005, 204:74-86.

69. Nyholt DR: A simple correction for multiple testing for singlenucleotide polymorphisms in linkage disequilibrium with each other. Am J Hum Genet 2004, 74:765-769.

70. Cardon LR, Bell Jl: Association study designs for complex diseases. Nat Rev Genet 2001, 2:91-99. 